\title{
Retraction Note: MALAT2-activated long noncoding RNA indicates a biomarker of poor prognosis in gastric cancer
}

\author{
F. Chen $\cdot$ Y. Tian $\cdot$ E-j Pang $\cdot$ Y. Wang $\cdot$ L. Li
}

Published online: 27 May 2020

(C) The Author(s), under exclusive licence to Springer Nature America, Inc. 2020

Retraction to: Cancer Gene Therapy

https://doi.org/10.1038/cgt.2015.6

published online 27 February 2015

The Editor-in-Chief is retracting this article [1]. Concerns were raised that the MALAT2 gene described does not exist. This has been confirmed by post-publication peer review: there is only one transcript, which is called MALAT1. None of the authors has responded to correspondence from the Editor-in-Chief or the Publisher about this retraction.

\section{Reference}

1. Chen F, Tian Y, Pang E, Wang Y, Li L. MALAT2-activated long noncoding RNA indicates a biomarker of poor prognosis in gastric cancer. Cancer Gene Ther. 2015; https://doi.org/10.1038/cgt.2015.6. 